\title{
El problema de la realitat en Mach, Schlick i Cassirer: reflexions crítiques al voltant de la filosofia de la ciència i del neokantisme
}

\author{
Michele Cardani \\ Societat Catalana de Filosofia \\ m.cardani@alumni.ub.edu
}

Data de recepció: $17-3-2019$
Data d'acceptació: $16-6-2019$

\section{Resum}

Al present article s'hi analitza la comprensió del problema de la realitat en les filosofies científiques d'Ernst Mach i Moritz Schlick i s'hi ofereix una interpretació crítica del problema de la transcendència en vista de les consideracions d'Ernst Cassirer dins del marc del neokantisme. S'hi mostra en quin sentit la doctrina d'Immanuel Kant pot ser llegida com una teoria del significat i per què solament mitjançant una dinamització de la Crítica de la raó pura és possible resoldre els problemes intrínsecs a les propostes de Mach i Schlick i plantejar més coherentment la relació entre coneixement i objecte.

Paraules clau: empiriocriticisme; positivisme lògic; neokantisme; ontologia; epistemologia; filosofia de la física; Mach; Schlick; Cassirer; Kant

Abstract. The problem of reality in Mach, Schlick, and Cassirer: Critical considerations about philosophy of science and neo-Kantianism

This article examines the comprehension of the problem of reality in the philosophies of Ernst Mach and Moritz Schlick and offers a critical interpretation of the problem of transcendence in light of Ernst Cassirer's neo-Kantian considerations. The reasons why Immanuel Kant's doctrine can be treated as a theory of meaning are shown. It is also argued that only through a revitalization of the Critique of Pure Reason is it possible to solve the problems related to Mach's and Schlick's perspectives and more coherently conceive the relationship between knowledge and object.

Keywords: empiriocriticism; logical positivism; neo-Kantianism; ontology; epistemology; philosophy of physics; Mach; Schlick; Cassirer; Kant

\section{Sumari}

0. Introducció

1. Elements factuals elementals i idealitzats

2. Problemes de transcendència
3. Més problemes de transcendència

4. Conclusions

Referències bibliogràfiques 


\section{Introducció}

Si volguéssim resumir amb un sol lema el principi cardinal de la revolució científica, podríem sens dubte recórrer a l'observació del científic vienès Ernst Mach, segons la qual «les ciències mostren un esforç decisiu per substituir, en la mesura que sigui possible, les dependències qualitatives amb dependències quantitatives» (Mach, 1906: 205) ${ }^{1}$. Sense por d'equivocar-nos, podem afirmar que aquesta idea travessa efectivament tota la història del pensament científic i filosòfic, fins al punt que el propi Immanuel Kant, com sabem, reconeix que "només hi ha ciència pròpiament dita mentre hi hagi matemàtiques» (Kant, 1968a: 470).

Evidentment, la reflexió entorn de les qualitats primàries i secundaries, així com la preponderància consegüent de les primeres en l'estudi de la natura, va influir no solament en l'evolució i el desenvolupament de les matèries científiques, sinó també en la pròpia filosofia, en la mesura que aquesta s'interroga sobre els conceptes i els problemes nous que les ciències ofereixen al pensament. Com diu el "diví Galileu» ${ }^{2}$, el llibre de la natura «està escrit en llenguatge matemàtic i els seus signes són els triangles, els cercles i altres figures geomètriques, sense les quals és humanament impossible entendre res» (Galilei, 1965: 38). Per tant, no n'hi ha prou de limitar-se a observar una revolució solament gnoseològica. És fonamental remarcar també un canvi radical a l'àmbit ontològic (com ho són, per exemple, el mecanicisme o el determinisme), que instaura un model de comprensió del món difús i acceptat almenys fins a James Clerk Maxwell, i desarticulat definitivament (en línia teòrica) per Albert Einstein.

El propi Mach és un dels protagonistes més rellevants d'aquest procés de canvi de perspectiva, fins al punt que Einstein li dedica el principi de Mach, que estableix la necessitat que hi hagi interacció entre la inèrcia d'un cos i tota la matèria restant de l'univers (cf. Bergmann, 1970; Goenner, 1970). El científic vienès, de fet, exposa els fonaments per establir una "gran física», en la qual totes les branques de les ciències naturals (des de la física fins a la psicologia) troben el seu lloc en una relació de coordinació, però no de subordinació, a la mecànica. Del que s'ha exposat més amunt és evident que la possibilitat de fonamentar aquesta "gran física» es troba en una concepció de la realitat que ha de poder oferir les assumpcions necessàries per al nou punt de vista sobre el món. Atesa la seva importància en el debat filosòfic de les últimes dècades del segle XIX i almenys dels primers trenta anys del segle Xx (però

1. Totes les traduccions al català són de l'autor d'aquest text. Agraeixo a la doctora Cristina Arimany Nardi la revisió lingüística de l'article, i als companys del Grup d'Estudis de Filosofia Clàssica Alemanya (GEFCA) i al doctor Marco Tamborini, els seus comentaris, que em van ser molt útils per millorar-ne el primer esbós.

2. Cf. Mascheroni (1863: 63): «QQui és aquell que, ple d’alts pensaments, | tanta filosofia porta a la seva cara? | És el diví Galileu, qui primer va rompre | l'ídol antic, i amb perill va fer sortir | les ments a la nativa llibertat; | nous ulls va posar en el front de l'home, Júpiter | va rodar amb estrelles; i després d'acusar el Sol | de natura corruptible, el va col-locar, | alta compensació, sobre un tron immòbil». 
també amb un ull posat en la discussió contemporània: cf. Schlagel, 1992; Massimi, 2011; Cardani i Tamborini, 2016; Midgley, 2018), la meva intenció en aquest article és plantejar filosòficament el problema i el debat entorn de la pregunta "què és la realitat?" partint de les consideracions que Ernst Mach proposa a Erkenntnis und Irrtum (Mach, 1906) i a Die Mechanik in ihrer Entwicklung: Historisch-kritisch dargestellt (Mach, 1889). Més concretament, en vista de les avaluacions i de les crítiques dirigides pels membres del Cercle de Viena i per Ernst Cassirer al propi Mach, s'intentarà jutjar la posició ontològica machiana; examinar la resposta de Moritz Schlick, i analitzar si les consideracions del propi Schlick són vàlides dintre del marc d'un empirisme coherent o si cal admetre unes altres assumpcions, com suggereix Cassirer ${ }^{3}$.

Sense anticipar totes les conclusions d'aquesta investigació, em limitaré aquí a evidenciar-ne els matisos més rellevants.

Abans de res, sabem que els membres del Cercle de Viena consideraven Mach el seu mestre intel-lectual, fins al punt que la seva relació amb el Verein va ser fonamental per facilitar-ne el naixement (Hahn et al., 2002). Tot i que existeixen diferències importants entre les posicions filosòfiques defensades pels membres del Cercle, la seva influència $i$ la unitat programàtica recíproques (tots s'esforçaven per «posar-se en contacte amb els moviments vius de l'època amistosament disposats per a la concepció científica del món i que s'apartaven de la metafísica i la teologia» (Hahn et al., 2002: 111) permeten justament esbossar un quadre interessant d'aquest moviment i dels seus interlocutors principals (tant històricament com teorèticament. Per a més detalls, cf. Haller, 1991).

Secundàriament, cal evidenciar que la crítica a l'empirisme és una part de la tasca que, almenys des de la publicació de la Crítica de la raó pura (Kant, 1968b), Kant atribueix a qualsevol recerca filosòfica en el sentit més estricte del terme. I no tant perquè el criticisme és essencialment la negació de l'empirisme - de fet, sabem que molts intèrprets han evidenciat que el propi Kant és empirista (cf., per exemple, Beneke, 1832; Tinland, 2017)—, sinó perquè aquest plantejament requereix almenys una conceptualització prèvia a la possibilitat d'assumir la realitat com a simplement donada. Per tant, si per respondre les qüestions plantejades entorn de la filosofia de la física cal (o com a mínim és oportú) retornar al criticisme (encara que mediat per Cassirer), pot ser que aquesta anàlisi pugui oferir importants elements de reflexió fins i tot per a la filosofia present i futura.

3. Tot i que Richard Avenarius és una altra figura rellevant per comprendre la gènesi del debat, en aquest article no dedicaré cap espai a discutir el seu pensament. Hi ha tres motius darrere d'aquesta decisió: $a$ ) la voluntat de no transformar l'anàlisi en una reconstrucció merament històrica; $b$ ) en les obres de Mach citades en aquest text (Mach, 1889, 1906), Avenarius hi apareix només tres vegades, de manera que no hi ha cap debat autèntic ni directe amb ell, c) a l'Allgemeine Erkenntnislehre (Schlick, 1925) és facil de veure com Schlick juga amb els dos pensadors criticant les seues doctrines com si fossin la mateixa, tal com observa Von Mises (1970), que en cert sentit no s'equivoca. 


\section{Elements factuals elementals i idealitzats}

Seguint el raonament que hem fet a la introducció, m'agradaria mostrar aquí els principis gnoseològics de la teoria de Mach, per poder després discutir els pressupòsits ontològics que la possibiliten (almenys en la línia teòrica) des del punt de vista científic i també filosòfic.

En la seva anàlisi del desenvolupament de la física i de la mecànica, Mach observa que el mecanicisme radicalitza inconscientment un dualisme de fons semblant al dualisme cartesià. Segons aquest dualisme, la matèria s'identifica amb la suma de les propietats mecàniques, mentre que tot allò que no disposa d'aquestes propietats (com ara l'esperit) és exclòs de l'interès de la ciència. Amb la finalitat de defensar la possibilitat d'una "gran física» capaç de superar (entre altres) també aquest escull, Mach suggereix que les distincions entre físic i psíquic, natura i pensament, han de ser reconduïdes a una experiència continua i homogènia (Mach, 1889, 1906).

En altres paraules: la finalitat de la ciència no és més que l'acomodació del pensament als fets. I com que els fets només ens són accessibles mitjançant les sensacions, l'únic mètode científic correcte és la construcció de conceptes justament a partir de les sensacions (cf. Rodríguez Consuegra, 1993). En aquest sentit, cal evocar la definició i el mètode més profund descrit per Mach per determinar el significat d'un concepte:

Una paraula o un concepte científic té la funció de recordar les connexions de totes les relacions de l'objecte definit indicades en la definició i d'atreure-les com si estiguessin lligades a un fil, fins a la consciència [...]. Qualsevol definició, naturalment, pot contenir al seu torn uns altres conceptes, de manera que només les últimes pedres de l'edifici conceptual, les més baixes, poden ser reduïdes a les reaccions sensibles de les quals són signes. Les paraules que no poden indicar conjunts d'experiències sensorials són incomprensibles, no tenen cap significat. (Mach, 1906: 23)

La reducció de la proposició, de la definició i del concepte a l'experiència immediata és absolutament necessària per determinar la validesa d'una associació en la consciència i, consegüentment, del seu valor epistemològic. Desenvolupar de manera lògica i deductiva el fil d'Ariadna que uneix concepte $\mathrm{i}$ sensacions permet, doncs, remuntar cap a totes les relacions que existeixen entre ells i assegurar la validesa empírica i científica del concepte mateix.

Com es veu, per a Mach sensació i percepció són els primers instruments cognoscitius que permeten determinar les representacions mentals a través de l'abstracció i de l'associació. De tota manera, els conceptes no tenen cap correspondència unívoca, directa ni estable amb els conjunts factuals als quals es refereixen, i són només recursos simbòlics per orientar-se en el confús embolic dels fets. Seguint el discurs de Mach, el contingut factual dels conceptes no ha d'induir a identificar les representacions mentals amb els fets que exposen, ja que les formacions psíquiques sempre són susceptibles de correccions — si és que no en necessiten directament. 
Les representacions, doncs, s’adapten gradualment als fets, i la integració conceptual d'un fet a partir d'un altre és la característica essencial del pensament científic. A través del procés d'abstracció, la ciència fa que les circumstàncies recíprocament dependents surtin a la llum, és a dir, separa de l'objecte d'investigació tot allò que sembla independent, en tant que secundari o indiferent, respecte a l'objectiu de la pròpia investigació. Mach observa, de fet, que les primeres dependències que observem són les més senzilles. Es tracta d'aquelles a les quals es pot accedir directament mitjançant els sentits. Únicament en un segon moment, gràcies al recurs a la representació conceptual, és possible remuntar, reconstruir i reconèixer les dependències més complicades i generals.

L'abstracció, efectivament, consisteix en l'operació a través de la qual quelcom és escollit com a objecte de percepció, atenció, observació, estudi, etc. i aillat de totes les altres coses amb les quals té alguna relació. Justament perquè abstreu, la ciència idealitza els seus objectes. Per això, si el que anomenem «objectes» no són més que una suma de sensacions tàctils i visibles lligades a les sensacions d'espai i temps, el domini de la ciència és aleshores les sensacions en el nivell de l'abstracció, és a dir, de la idealització, o sigui, d'un ordre numèricament (quantitativament) graduat.

Arribem així a la formulació de la realitat que Mach ofereix en Erkenntnis und Irrtum (Mach, 1906). La realitat està formada per tot allò que és immediatament present a l'espai. Però si l'experiència ha de ser contínua i homogènia, significa que la mateixa realitat és la suma d'innombrables relacions entre elements: els constituents últims de l'ontologia machiana són elements factuals elementals i idealitzats. No existeix cap cosa aillada, cap cosa en si. Per afirmar que allò que interessa a la ciència és la dependència funcional (en sentit matemàtic) dels fets, Mach necessita descompondre la realitat en Elemente, els quals, com hem vist, no són el resultat d'una observació ingènua:

La descomposició del soroll en sensacions sonores senzilles, de les sensacions tàctils en una multiplicitat de sensacions parcials, de les sensacions lluminoses en sensacions de colors primitius, etc., ja és part de la ciència moderna. (Mach, 1906: $12 \mathrm{n}$ )

L'estudi dels elements i de les seves dependències recíproques es transforma, segons Mach, en la representació de les relacions a través de funcions matemàtiques. La introducció de funcions matemàtiques i de l'anàlisi quantitativa és fonamental. De fet, encaixa perfectament en el seu projecte científic, ja que "subordinant un fet a un concepte ho simplifiquem, perquè excloem totes les característiques no essencials a la finalitat de la investigació» (Mach, 1906: 136), i lliga coherentment amb l'assumpció epistemològica analitzada abans, segons la qual als instruments del pensament no els ha de ser atribuïda cap realitat extramental. Segons Mach, considerar fonaments del món real els conceptes intel-lectuals amb els quals representem el mateix món és un error molt greu. Seria comportar-se 
Com aquell que, tenint experiència del món només a través del teatre, descobrís entre bastidors l'equipament mecànic i conclogués que el món real és un escenari i que tot pot ser conegut un cop hem conegut l'escenari. (Mach, 1889: 476)

Es comprendrà, doncs, que l'empiriocriticisme machià i la reducció de l'ontologia a elementare, idealisierte i Tatsachenelemente no amaguen cap cosa en si, encara que ens trobem en el nivell de la idealització, ni suggereixen un positivisme autèntic (cf., per exemple, Von Mises, 1970), i la realitat fisiològica $\mathrm{i}$ intuïtiva equivalent als elements que hi ha més a prop de l'experiència immediata i la realitat construïda amb l'abstracció i la idealització dels elements representen simplement nivells diferents del contínuum real que constitueix el món en la totalitat de les seves manifestacions.

En altres paraules, les ciències han d'establir "què hi ha», però han de recórrer a instruments ficticis (com ara els conceptes o les funcions matemàtiques), que apel.len a experiències econòmicament ordenades sense postular cap món metafísic de substàncies immutables (encara que científiques) que es col-loquin més enllà de l'àmbit de la percepció.

\section{Problemes de transcendència}

La progressió contínua d'entitats reals que Mach anomena «elements» és de caràcter immanent tot i la seva idealitat, ja que no amaga cap realitat metaempírica, sinó únicament una xarxa de relacions que ha de ser investigada per la ciència.

L'aparent simplicitat $\mathrm{i}$ coherència d'aquestes assumpcions mereix sens dubte una reflexió més profunda: la immanència del sistema machià, de fet, implica certes dificultats $i$ certs problemes de transcendència que no poden ser ignorats. Per comprendre'ls, i per entendre les crítiques de Schlick a Mach, em referiré a l'anàlisi del concepte d'espai, tan important en física com en la història de la filosofia.

Tot i que, segons Mach, l'espai fisiològic no coincideix amb l'espai de la geometria, la geometria s'ocupa d'objectes ideals nascuts a la nostra ment gràcies a l'interès espacial humà pels cossos físics. Coherentment amb el projecte d'una "gran física» i d'una epistemologia graduada, la diferència no és substancial, sinó progressiva: en altres paraules, l'espai geomètric és un perfeccionament biològic i evolutiu, és una "complicació» de la ment, però no és cap objecte diferent de l'espai fisiològic. L'oposició fisiologicogeomètrica correspon, doncs, a un contínuum de determinacions que progressivament es van fent més complicades idealitzant el propi objecte. Tot això, clarament, depèn del fet que entre intuïció i coneixement conceptual no hi ha cap diferència qualitativa. Es tracta solament de dos moments diferents i ordenats del procés cognoscitiu.

També Schlick defensa la tesi de l'origen sensorial de totes les experiències espacials, de manera que no refuta a priori l'argument machià. No obstant això, la seva concepció de l'epistemologia científica s'allunya molt de l'ideal de 
Mach: per a Schlick, entre intuïció i coneixement no hi ha cap diferència quantitativa, sinó qualitativa. De fet, segons la seva caracterització del coneixement, conèixer significa 'relacionar dos termes': «alguna cosa que és coneguda, i com a què és coneguda» (Schlick, 1925: 76). En la intuïció, en canvi, l'única informació que tenim disponible és simplement compresa: des del punt de vista cognoscitiu, la intuïció és una contradictio in adjecto. En la seva Allgemeine Erkenntnislehre, el filòsof alemany es demana:

¿És cert que apareixen problemes insolubles —és a dir: contradiccions insuperables amb els requeriments $\mathrm{i}$ les regles de les ciències particulars- si considerem real no solament allò que ens és donat, sinó també tot allò que pot reivindicar una determinada orientació espacial i temporal sobre la base d'aquells requeriments i d'aquelles regles? ¿És veritat que aquelles contradiccions poden ser evitades únicament restringint el concepte de realitat retornant al seu origen, o sigui, allò que experimentem de forma immediata? (Schlick, 1925: 182)

La resposta evidentment és negativa: per a Schlick, amb la derivació de les experiències espacials des de percepcions sensorials no n'hi ha prou per caracteritzar l'espai objectiu del físic. Amb això, Schlick no està abandonant l'arrel empírica del coneixement: la insuficiència de l'espai fisiològic i intuïtiu depèn del fet que les dades de camps sensorials diferents són incompatibles entre si. Per exemple, l'espai de les sensacions tàctils és diferent toto genere de l'espai de les sensacions òptiques (cf. Schlick, 1920). De fet, no solament les percepcions visives, sinó també les que corresponen als altres sentits tenen propietats espacials: justament per això, a cadascuna li correspon un espai constituït de forma diferent. A més, Schlick observa que fins i tot dins d'un mateix sentit poden donar-se espais diferents. Si considerem la vista i pensem en un cub, aquest objecte canvia la seva forma en relació amb el punt de vista (per exemple: la cara o la distància) i pot aparèixer com una cosa diferent en moments successius (si es fa fosc o si hi ha massa llum).

Ara bé, és veritat que el propi Mach reconeix que cadascú té el seu propi espai intuïtiu particular, mentre que l'espai geomètric és comú i objectiu (Mach, 1906). Però per a Mach aquest espai és idealitzat i abstracte, mentre que per a Schlick depèn dels objectes físics, o sigui, hi té una relació directa. Aquesta diferència s'entendrà clarament retornant a l'exemple del cub: si transcendim la immanència de la percepció isolada, és possible atribuir a l'objecte una forma constant. No podem assignar als objectes físics un espai intuïtiu que coneixem únicament a través de les sensacions, «sinó només un ordre de tipus no intuïtiu que es diu espai objectiu» (Schlick, 1920: 79). De fet, cap conjunt d'elements percebuts des de punts de vista diferents és el propi cub: "tots aquells conjunts —els quals depenen de les condicions d'illuminació, de la distància, etc. - representen únicament l'objecte, és a dir, hi estan coordinats» (Schlick, 1925: 249-250). Tot i això, si a més de mirar el cub també el toquem amb un dit, els dos sentits comparteixen una dada espacial comuna, és a dir, el punt de contacte: «aquestes dues vivències, que són independents, són coordinades per un sol "punt" de l'espai transcendent" 
Michele Cardani

(Schlick, 1925: 250) mitjançant un mètode que Schlick anomena «mètode de les coincidències» ${ }^{4}$.

Aquesta transcendència en la immanència permetria, doncs, afirmar que és el mateix cub l'objecte que es troba en contacte amb el dit, a una certa distància de l'altra mà, lluny en certa mesura dels ulls, etc. En aquest sentit, l'única transcendència que Schlick postula és la transcendència del realisme empíric, segons la idea que l'objecte és susceptible de determinacions empíriques potencialment infinites. Schlick anomena aquest conjunt de processos i estats «cosa en si». Es troba aquí plantejat el problema de si existeixen entitats més enllà del que pròpiament ens és donat. Dit d'una altra manera, si objectes que no pertanyen a l'àmbit de la sensació poden ser considerats reals ${ }^{5}$.

Mentre que per a Mach la validesa d'un judici, com hem vist, depèn de la seva capacitat de «recordar les connexions de totes les relacions de l'objecte definit indicades en la definició, i d'atreure-les, com si estiguessin lligades a un fil, fins a la consciència» (Mach, 1906: 23), amb la introducció del concepte de cosa en si Schlick obre un espai de reflexió molt diferent:

Els objectes que designem amb els conceptes de les nostres ciències de la natura (cos, àtom, camp elèctric, etc.) ja no són idèntics als conjunts d'elements reals, sinó que són tan reals com aquells, i ho continuen sent no obstant els elements no ens són donats. Les propietats i les relacions d'aquests objectes, de fet, no ens són donades, sinó deduïdes. I això és cert en el mateix sentit i grau per a tots els objectes, tant els electrons com el pa que tenim sobre la taula. (Schlick, 1925: 200)

4. No es tracta simplement d'una crítica a Mach, sinó també a Kant i a Edmund Husserl: el text de Coffa (1991) pot resultar molt interessant per aprofundir aquest tema. Sense demorar-nos massa en aquesta qüestió, cal remarcar que un dels punts forts de l'argumentació de Schlick és la referència a la teoria de la relativitat d'Einstein, la qual demostra que l'espai geomètric real no té res a veure amb les nostres percepcions o intuïcions. Segons Henry Poincaré, que és una referència important per al pensament de Schlick, «els axiomes de la geometria no són més que definicions disfressades. Consegüentment, hem d'entendre que la qüestió "es la geometria euclidiana certa?" no té cap sentit. Tampoc en té preguntar-se si el sistema mètric és veritable i les mesures antigues, falses; si les coordenades cartesianes són veritables i les coordenades polars, falses. Una geometria no pot ser més veritable que una altra, solament pot ser més còmoda» (Poincaré, 1917: 67). Paral-lelament, Schlick observa que «la geometria de la vida quotidiana ha sigut sempre euclidiana, i fins fa poc es considerava la base per a tots els àmbits de la ciència de la natura. Tot $\mathrm{i}$ això, la física recent, amb una de les seves construccions més belles i ardides - la teoria einsteiniana de la gravitació-, ha arribat a la conclusió que, si volem descriure la natura amb la màxima exactitud mitjançant les lleis més senzilles, és impossible fer-ho amb determinacions mètriques euclidianes. Segons aquella teoria, hem d'usar una geometria diferent en cadascun dels punts del món, una geometria que depèn de l'estat físic d'aquell punt (o sigui, del potencial gravitacional que hi ha en aquell punt). Segons les últimes investigacions d'Einstein, és molt probable que la millor manera de concebre l'espai de l'univers en conjunt consisteix a considerar-ho dotat de propietats aproximadament esferiques» (Schlick, 1925: 324-325) (cf. també Schlick, 1920).

5. Aquests objectes han de considerar-se "coses en si» sense la necessitat de postular cap entitat «absoluta» o metafísica (cf. Parrini, 2002). 


\section{Schlick continua afirmant:}

quan veiem la Lluna que s'acobla amb una estrella en un punt de la seva circumferència, és veritat que, segons els nostres ulls, l'estrella coincideix amb el marge de la Lluna, però sabem del cert que no es troba al mateix punt on hi ha la Lluna, ja que està situada extremament lluny d'ella». (Schlick, 1925: 251)

De la mateixa manera, la ciència formula judicis entorn de l'interior del Sol, dels electrons, de les forces de camp magnètiques, etc.

Aquestes observacions són d'una importància fonamental si considerem la relació amb la filosofia de Mach. La posició ontològica machiana, segons Schlick, és tan absurda com afirmar que «el llapis que tinc la mà ha de ser real, però les molècules que el constitueixen han de ser pura ficció» (Schlick, 1920: 86), però si el judici pot estendre la seva validesa més enllà de la simple percepció, cal assegurar que hi ha una certa relació entre l'àmbit gnoseològic i la realitat.

A l'Allgemeine Erkenntnislehre (Schlick, 1925), el filòsof alemany compara la seva idea d'epistemologia a una xarxa que fluctua en el pla de l'experiència i que és constituïda per nusos (els conceptes) i cordes (connexions, judicis a posteriori, definicions, convencions) ${ }^{6}$. Dins d'aquesta xarxa, els judicis cognoscitius han de designar unívocament els fets: «la univocitat és la sola virtut essencial per a una coordinació. Ja que la veritat és l'única virtut dels judicis, la veritat ha de consistir en la univocitat de la designació» (Schlick, 1925: 57). Si bé és cert que "les ciències han desenvolupat, des de fa temps, mètodes determinats per controlar la univocitat de la designació dels fets mitjançant judicis» i que aquests mètodes són «els mètodes de verificació» (Schlick, 1925: 149), amb això encara no n'hi ha prou.

Des d'un cert punt de vista, de fet, la idea de Mach que cal que hi hagi una connexió entre judici, objecte i sensació podria contenir in nuce la mateixa concepció schlickiana de la necessitat d'una verificació empírica per poder determinar el valor significatiu d'un judici. Schlick afirma:

les ciències exactes semblen $[\ldots]$ una torre Eiffel que, mitjançant molt pocs punts de suport, s'eleva lliure i àgil fins a les altures aèries dels conceptes més generals, des dels quals únicament és possible dominar els fets individuals amb més perfecció. (Schlick, 1925: 73)

Però, com hem vist, hi ha una diferència radical respecte a Mach, ja que la posició defensada per Schlick implica l'existència d'objectes no percebuts directament, tot i que poden existir en un temps determinat. Ara bé, si els conceptes designen unívocament objectes i si la validesa d'un judici és el mètode de la seva verificació empírica, demostrant la veritat d'un judici cognoscitiu podem concloure que l'objecte designat existeix.

6. Cap «corda» té validesa a priori, independentment de com s'entengui el terme (universal i necessari, com fa Kant, o constitutiu, com fa Hans Reichenbach, un altre representant important del debat científic a Alemanya) (cf. Parrini, 2002). 
Però, com podem estar segurs que entre els objectes subsisteixen les mateixes relacions que són epistemològicament vàlides per al sistema de judicis? Per respondre aquesta qüestió, Schlick proposa la teoria de l'isomorfisme. Més enllà de tota possible polèmica terminològica ${ }^{7}$, el fet que Schlick utilitzi el mot isomorfisme no ha d'alarmar, ja que es tracta d'un terme matemàtic i lògic que indica una relació entre relacions homogènies.

En altres paraules, indica simplement una relació biunívoca entre relacions dintre d'un sistema. Segons Schlick, l'ordre sobreentès pel terme és tan general que «seria absurd dir de qualsevol cosa que no en té. Dir que un fet té una estructura és com no dir-ne res: és una mera afirmació tautològica» (Schlick, 1938: 158). No seria, doncs, cap assumpció metafísica, ja que, a més, un dels dos termes de la relació, el llenguatge, és constituït per assercions i judicis. Al cap i a la fi, aquests són fets del món real: «el món està format per fets, els fets tenen una estructura, i les nostres proposicions representaran els fets correctament, seran certes, si tenen la mateixa estructura» (Schlick, 1938: 224).

En una teoria científica, les entitats involucrades formen patrons o estructures que les funcions matemàtiques expliciten. Si acceptem que aquestes funcions expressen relacions entre fenòmens, aleshores tenim una informació viable dels patrons o de les estructures, és a dir, de la realitat.

Sense aquesta identitat estructural no hi hauria cap correspondència. Sense correspondència no té lloc cap designació. Però no és possible emetre cap judici cognoscitiu que no sigui designatiu. Schlick, de fet, observa que, amb un nombre finit de signes, podem realment designar una quantitat infinita de fets passats, presents i futurs: vist des d'un altre punt de vista, designar fets nous amb signes vells significa atribuir al judici una validesa que va més enllà de les experiències acumulades fins al moment en què es formula el judici mateix. Les condicions de possibilitat d'aquesta característica del pensament es troben en l'isomorfisme: podem ampliar la validesa d'una asserció sobre un fet i estendre-la fins a casos que encara no hem imaginat, perquè suposem sempre que el judici conservarà una identitat estructural amb els fets futurs. Aquesta funció del pensament, per tant, és transcendent respecte a les dades sensibles immediates, però no ho és respecte a les relacions estructurals i formals que defineixen la realitat $\mathrm{i}$ amb les quals el judici ha de preservar una relació biunívoca.

Amb certa innocència (o potser amb malignitat retòrica) i defensant una posició quasi humeana (cf. Schlick, 1925: 2009), Schlick diria:

7. Sabem que els membres del Cercle de Viena no simpatitzaven gens amb la metafísica ni amb el seu llenguatge fosc. Rudolf Carnap afirmava, per exemple, que «els metafísics — tant si són defensors del monisme, del dualisme, del pluralisme, de l'espiritualisme, del materialisme, com de qualsevol altre -isme - es fan preguntes sobre l'essència de l'univers, de la realitat, de la natura, de la història, etc.» (Carnap, 1995: 22); en canvi, els membres del Cercle rebutjaven aquests dubtes com a problemes aparents. Amb tot, veurem que, no obstant les justificacions paral-leles de Bertrand Russell, Ludwig Wittgenstein, David Hilbert, Richard Dedekind i Henry Poincaré, sí que oculta problemes molt importants (cf. Coffa, 1991; Friedman, 1999, 2010; Gower, 2010; Livingston, 2002; Piana, 1971). 
també l'empirista creu en la unitat de la natura i en la conformitat de l'experiència envers les lleis. Simplement pensa que la validesa i la necessitat objectiva d'aquella unitat i d'aquella conformitat no poden demostrar-se mitjançant una deducció transcendental o de qualsevol altra manera. (Schlick, 1921:102)

Però, si bé és cert que, des d'un cert punt de vista, Schlick va més enllà de Mach, ¿ podem acceptar que un empirista coherent i amb una impostació tan científica cregui en la unitat de la natura? Probablement sí, sempre que el terme no assumeixi cap rellevància gnoseològica o ontològica. En el cas de Schlick, però, més que d'una creença es tracta d'una condició, i és aquí on comencen els problemes.

\section{Més problemes de transcendència}

Hem vist que el ficcionalisme de Schlick consisteix en una relació entre una visió designativa del coneixement i la seva aversió per la síntesi a priori.

La doctrina de l'isomorfisme, però, introdueix un element (i un problema) ulterior: si podem acceptar que funcions matemàtiques designin la realitat, ¿podem admetre també que n'hi ha prou de postular una identitat estructural en el sentit de Schlick per justificar la seva teoria del coneixement i la seva proposta ontològica? En altres paraules, cal plantejar, com fa Cassirer, la demanda següent:

Si els judicis no són més que connexions de signes, i els signes no són més que convencions i ficcions, com podem, en aquest «joc de símbols», arribar a la certesa que hi ha un «món» transcendent i que hi ha relacions fixades objectivament? (Cassirer, 2004: 60)

Aquesta és la pregunta de fons que Schlick no pot respondre sense recórrer a una petitio principii: «la realitat no pot donar-se mai mitjançant el coneixement [...]. Existeix abans de tot coneixement. És allò que designem, allò que és abans de tota designació» (Schlick, 1925: 158).

Segons Schlick, el «mètode de les coincidències» i la «senyoria del nombre» ${ }^{8}$ permeten demostrar la possibilitat de la transcendència en el realisme i no poden de cap manera ser comparades de facto amb cap teoria constructivista. Amb tot, cal reconèixer que, malgrat que Schlick rebutja l'opinió kantiana que existeixen principis constitutius a priori (universals, necessaris), aquella transcendència no podria donar-se sense admetre, de iure, un cert sistema de coordinació.

És molt curiós, però alhora no sorprenent, que Michael Friedman observi que una teoria del judici i del coneixement d'aquest tipus "és kantiana (i antiempirista) pel que respecta al seu "holisme" i "formalisme" (Friedman, 1999: 20n). Obviament, Friedman sap molt bé que «Schlick va rebutjar sempre la

8. És el propi Schlick qui parla a l'Allgemeine Erkenntnislehre (Schlick, 1925) d'una Herrschaft $\operatorname{der} Z a h l$ per descriure el seu mètode cientista de determinació de la realitat. Com es veu, en aquest sentit la seva proposta no es diferencia de la filosofia de Mach. 
síntesi a priori i la teoria kantiana de espai i temps» (Friedman, 1999: 20). Tot i això, aquesta interpretació de Friedman, heretada de Cassirer ${ }^{9}$, no és inapropiada. Un cop que s'ha abandonat l'empirisme més radical (representat per Mach) ${ }^{10}$, s'ha admès una realitat no percebuda i s'ha postulat una estructura formal que garanteix la transcendència del judici cognoscitiu (encara que no a priori en un sentit kantià), el pas cap a una teoria de la constitució objectiva de la realitat és molt breu. A més, el propi Schlick reconeix, en una carta a Cassirer de 1927, que el seu "concepte de "cosa en si" coincideix amb el concepte kantià d'objecte empíric» (Schlick, 2009: 95).

En línia amb aquests arguments, podríem doncs afirmar que allò que Schlick anomena "transcendència» no és diferent de la immanència kantiana, segons la idea que "cap cosa és un objecte per a nosaltres si no pressuposa com el conjunt de tota la realitat empírica com a condició de la seva possibilitat» (Kant, 1968b: 391 (A582/B610)).

Cassirer està d'acord amb Schlick i també considera insuficient la posició immanentista de Mach (qui, com hem vist, pretén obtenir les lleis analítiques i matemàtiques des de la percepció immediata i resoldre l'objecte del coneixement en relacions entre elements). Com Schlick, ell també reconeix la necessitat de determinar les propietats constants de fenòmens constants. En el seu cas, però, la possibilitat d'una caracterització de l'objecte pot dependre únicament d'una funció del judici que garanteix la permanència de la realitat empírica:

Enmig del caos temporal de les sensacions, nosaltres establim, prescindint del temps, connexions i coordinacions estables, i són elles les que formen l'estructura fonamental de la realitat empírica. Perquè és sempre una funció del judici allò que assegura la permanència de l'ésser empíric. (Cassirer, 1910: 330-331)

És clar que, en aquest context, "prescindir del temps» no implica fer una extrapolació de l'objecte de la sèrie temporal. Significa simplement que, si no fixem aquella estabilitat, tot moment suprimiria el moment precedent $\mathrm{i}$, amb ell, totes les veritats fixades i vàlides per a aquell moment. Es tracta, mutatis mutandis, d'una paràfrasi molt ben feta per Cassirer de la segona analogia kantiana:

Jo percebo que els fenòmens se segueixen els uns als altres, és a dir, que l'estat de les coses en un moment és oposat a l'estat anterior. En realitat el que faig és, doncs, enllaçar dues percepcions en el temps. Ara bé, l'enllaç no és obra del simple sentit ni de la intuîció, sinó que és, en aquest cas, producte d'una facultat sintètica de la imaginació [...]. Amb la simple percepció queda sense determinar quina és la relació objectiva dels fenòmens que se succeeixen els uns als altres. (Kant, 1968b: 167 (B233))

9. Cf. també Gower (2010), qui també defensa aquesta lectura.

10. El propi Schlick es demana si entre sensisme i criticisme "tertium non datur». Evidentment, la seva resposta és negativa i el seu sistema és presentat com una tercera via (cf. Schlick, 1921). 
De fet, acceptant la instància neokantiana i assumint l'esperit (i no la lletra) de la primera Critica (Kant, 1968b), és possible comprendre com i per què la filosofia crítica pot resoldre el problema presentat abans, ja que atribueix una forma nova a la qüestió de l'acord entre la representació i el seu objecte. Que «l'experiència no és possible sense la representació d'una connexió necessària de percepcions» (cf. Kant, 1968b) és un principi que podria acceptar el propi Schlick, qui, efectivament, com hem vist, ho accepta. El problema, en el seu cas, és un altre.

Sabem bé que per a Kant «necessitat i universalitat rigorosa» són «els signes segurs del coneixement a priori» (Kant, 1968b: 29 (B4)), és a dir, l'objecte de la filosofia transcendental. Sabem també que la concepció kantiana de la física i de la geometria està fortament lligada a la teoria newtoniana que dominava en el seu temps. Així doncs, és clar que, en vista dels progressos de la física, el caràcter apodíctic de l'apriorisme kantià ha de ser posat en dubte. Però això no implica que la tasca de fons del criticisme hagi de ser rebutjada: l'anterioritat del judici a priori, és a dir, la seva independència de qualsevol fet particular de l'experiència, no és cronològica, sinó lògica. Les facultats a priori descrites per Kant poden efectivament parlar dels fets sense recórrer a l'experiència només perquè ells mateixos la constitueixen.

En altres paraules:

Per al criticisme hi ha determinats principis superiors que aquest moviment considera les condicions de possibilitat de l'experiència i les condicions de possibilitat del seu objecte. Aquests principis no són derivats de l'experiència, però valen per tota l'experiència, ja que no s'hi expressa més que el significat lògic de l'objecte de l'experiència, essent l'estructura de sentit característica d'ell mateix. (Cassirer, 2004: 63)

Cal, doncs, admetre que, en aquest sentit, Schlick no és capaç de justificar la seva posició: si veritablement el punt de vista de les seves consideracions és el mateix que el de David Hume i si «no és possible anar més enllà» (Schlick, 1925: 366; cf. també Schlick, 2009), aleshores Schlick també hauria d'acceptar les conseqüències més radicals de la teoria humeana. Al contrari, la transcendència en la immanència, basada en el supòsit que la natura és contínua i formada per lleis uniformes, implica un conflicte de fons. El sistema de Schlick «és deixat a la mercè de dues forces contrastants, que l'estiren ara cap a una concepció empirista del problema fonamental del coneixement, ara cap a una concepció criticista» (Cassirer, 2004: 64).

En canvi, l'alternativa neokantiana de Cassirer mostra la seva força per dos motius almenys:

1. En l'empremta de Kant, i d'acord amb les exigències de la filosofia científica, el concepte d'ésser no és expressat com a substància, sinó com a funció matemàtica: «l'únic que coneixem de la matèria són pures relacions» (Kant, 1968b: 229 (A 285/B 341)). Com que per a Kant res no pot ser objecte si no es pressuposa el conjunt de tota la realitat empírica, així, segons Cassirer: 
El judici empíric singular conté ja com a postulat implícit la idea de la determinació completa de la natura, que es troba com a resultat final en el sistema complet de l'experiència [...]. Com que el caràcter general de la posició i de la distància pertany al punt singular, el caràcter universal de la llei també pertany a l'experiència singular [...]. El passatge de la singularitat a la totalitat és possible perquè ja des del principi la relació amb el tot no és exclosa, sinó mantinguda. A més, necessita únicament ser isolada i posada a la llum conceptualment. (Cassirer, 1910: 328)

Aquí, per tant, els principis de la revolució científica que hem recordat a la introducció són conservats o, més ben dit, potenciats.

2. De fet, la matematització i la dinamització de l'apriorisme kantià permeten també reivindicar una possible solució al problema de la correspondència entre coneixement i realitat. Únicament si introduïm un criteri últim de significativització, o sigui, una funció general constitutiva, podem definir el valor d'una determinada experiència, és a dir, conèixer:

Si [...] agrupem cireres i carns conjuntament sota els atributs de vermell, sucós i comestible, no obtenim cap concepte lògicament vàlid, sinó una combinació de paraules desproveïda de sentit i bastant inútil per a la comprensió de casos particulars. Així, doncs, queda clar que no n'hi ha prou de la regla formal general en si: al contrari, hi ha d'haver sempre una referència implícita a un altre criteri intel-lectual per complementar-la. (Cassirer, 1910: 8)

Segons aquesta interpretació, la teoria de Kant reivindica doncs un paper fonamental, que és el de l'expressió de la connexió en la qual es presenten els continguts mateixos de l'experiència sensible. Això és possible perquè reivindica per qualsevol concepte cognoscitiu la universalitat concreta del concepte matemàtic, és a dir, la validesa universal del particular subsumit sota un principi d'ordre serial. En línia amb Kant, el significat apareix només quan el concepte és reconegut com l'expressió d'una relació sobre la qual es basa la unitat i la connexió contínua dels elements d'un conjunt. En conseqüència, el problema de la transcendència no resol únicament la diatriba amb Schlick. Com hem vist, constitueix un punt fonamental de continuïtat amb Kant i resulta fonamental també per resoldre el problema del mètode inductiu. Allò que a primera vista pot aparèixer isolat o sense connexions evidents, es mostra com un símbol en una organització sistemàtica exhaustiva. Seguint el camí obert per Kant, quan l'objecte no és determinat com una substància absoluta més enllà del coneixement, sinó com un resultat plasmat pel progrés de l'experiència, tota transcendència quedarà eliminada. Veritablement, és clar que des de la perspectiva del subjecte empíric aquesta discontinuïtat epistemològica subsisteix, però quan assumim el punt de vista de la filosofia crítica i dels seus principis, tot es resol en la immanència. Com diu el propi Cassirer, "la proposició que l'ésser és un producte del pensament no conté cap referència a relacions causals físiques o metafísiques, sinó que indica merament una relació purament funcional» (Cassirer, 1910: 395). 
En tot cas, seria profundament injust limitar l'abast de la filosofia de Cassirer a una lògica de l'experiència objectiva i del coneixement objectiu del món. Si les pròpies ciències físiques mostren la necessitat de no recórrer únicament a un sistema de símbols i d'obrir-se a una multiplicitat metodològica i ontològica (cf. Cassirer, 1937), caldrà segurament realitzar una operació similar en l’àmbit de les ciències de l'esperit. Així com, segons Kant, «enteniment i raó tenen dues legislacions diferents sobre el mateix territori, sense que l'una pugui perjudicar l'altra» (Kant, 1968c, 175) i, per tant, podem investigar amb confiança segons diferents principis, de la mateixa manera, segons Cassirer:

La teoria no pot ni ha de ser circumscrita al coneixement científic del món, ni tampoc a un sol punt culminant, lògicament excel-lent, del coneixement mateix, sinó que sempre hem de buscar-la allà on s'operi una forma específica de configuració, de constitució d'una determinada unitat de «sentit». (Cassirer, 2002: 18)

Es tracta, com sabem, del programa de la filosofia de les formes simbòliques, el qual, lamentablement, no pot ser discutit en aquest article. Tot i això, cal mencionar almenys la seva força reivindicant un retorn a Kant i als seus principis fonamentals: «la primacia de la funció sobre l'objecte» (Cassirer, 2001: 9) que ens ha interessat fins ara.

\section{Conclusions}

Hem començat aquest article recordant la importància de la matemàtica per a les conseqüències gnoseològiques i ontològiques de la revolució científica i mencionant un acord màxim entre Kant i Mach en aquest aspecte. Com hem vist, també Schlick i Cassirer comparteixen aquest principi.

Després, hem analitzat l'empiriocriticisme machià i n'hem evidenciat els aspectes principals: la reducció de la realitat a uns conjunts d'elements senzills, la dependència del sistema conceptual de l'àmbit de la sensació i la reducció consegüent de les lleis i dels objectes de la ciència a mers instruments del pensament.

Així doncs, hem discutit l'intent de Schlick de superar la posició de Mach per reivindicar la capacitat efectiva de la ciència i de la filosofia de determinar què és la realitat. La concepció semiòtica del coneixement, així com el realisme que caracteritza la seva doctrina, pretenen demostrar la possibilitat de construir, en la immanència del món dels fets, un ordre transcendent en el qual la realitat efectiva d'entitats no percebudes (és a dir, tots els objectes de les ciències) és garantida. En aquest recorregut, hem mostrat diverses vegades l'aversió de Schlick per la síntesi a priori de Kant.

Llavors, assumint el punt de vista de Cassirer, hem discutit una qüestió molt important, ja que l'explicació de Schlick sobre com és possible conciliar la seva posició amb una teoria del coneixement científic i una teoria de la realitat és insuficient. Cassirer observa que el resultat més autèntic de la teoria kantiana consisteix en l'intent de respondre a aquell problema. De fet, hem 
mostrat que la qüestió crítica és una pregunta entorn de com és possible acordar l'apriorisme amb les condicions formals de l'experiència en el conjunt.

Aquesta discussió, doncs, resulta interessant com a mínim per quatre raons:

1. En primer lloc, perquè permet enfocar una sèrie de problemes filosòfics i científics que van influenciar en el debat que va tenir lloc durant els primers anys del segle xx i implicar-hi pensadors rellevants com ara Carnap, Cassirer, Dedekind, Herbart, Hilbert, Hume, Husserl, Kant, Mach, Poincaré, Reichenbach, Russell, Schlick, Wittgenstein i molts més que no hem pogut mencionar aquí. Sabem molt bé que el quadre pintat en aquest article no pot captar la complexitat d'aquell panorama, tot $\mathrm{i}$ això resulta igualment molt útil per comprendre l'evolució de certs moviments filosòfics que, per exemple, van portar a la separació entre l'escola analítica i l'escola continental (cf. Friedman, 2000).

2. En segon lloc, aquesta anàlisi pot ser rellevant per estudiar el debat contemporani entre realistes $i$ antirealistes en l'àmbit de la filosofia de la ciència. Si fins i tot per a un realista cientista com Schlick «l'adquisició del concepte de realitat és una tasca de la ciència», però correspon a la filosofia "considerar els principis i les condicions del compliment d'aquella tasca» (Schlick, 1925: 367), podem concloure que els plantejaments massa reduccionistes o descriptius (típics especialment de la tradició analítica) no són capaços de mostrar tota la complexitat filosòfica dels problemes en joc. Avui assistim encara a la proliferació d'un empirisme científic radical (com en el cas de Bas van Fraassen, per exemple) i a respostes de teories realistes més moderades, les quals, però, es limiten a realitzar una anàlisi de facto $\mathrm{i}$ mai de iure, com en canvi seria oportú segons demostra aquest article (cf., per exemple, Bogen i Woodward, 1988; Glymour, 2000; French i Ladyman, 2003; Bogen, 2009; Massimi, 2011; Cardani i Tamborini, 2016).

3. En tercer lloc, hi va haver unes altres branques de l'especulació filosòfica que es van beneficiar de les reflexions neokantianes. El cas específic de la biologia mostra, per exemple, una necessitat històrica i teòrica a l'hora de tornar a considerar la importància de la biofilosofia kantiana i neokantiana per l'evolució d'aquesta ciència al segle xx. Si, com afirma Michela Massi$\mathrm{mi}$ «qualsevol investigació entorn de les fundacions de l'espaitemps, de la natura de la causació o d'organismes vivents en la filosofia de la biologia hauria de plantejar-se i discutir-se d'una manera que ens permetés dotar de significat la pregunta "com és possible el coneixement científic?"” (Massimi, 2009: 302), en vista d'aquest article és clar que no és possible fer-ho sense tenir en compte Kant i les interpretacions neokantianes de la seva doctrina (cf. Tamborini, 2018) ${ }^{11}$. De fet, el passatge des d'un plantejament merament descriptiu cap a una «arqueologia de la natura» (Kant, 1968c,

11. El propi Cassirer, per exemple, mostra com l'evolució del debat històric i crític entorn de la biologia té molt a veure amb les interpretacions de Kant que es van donar després de la «caiguda» de Hegel (cf. Cassirer, 2000). 
428n) és esbossat sistemàticament pel propi Kant (cf. Tamborini, en curs). Cal subratllar també que la teoria de la forma orgànica que Kant presenta a la Crítica del judici (Kant, 1968c) va exercir, a través de Johann W. Goethe, un impacte molt important sobre les ciències durant els segles XIX i XX i sobre el propi Cassirer (cf. Esposito, 2016; Liano, 2016; Zammitto, 2018).

En l'àmbit de la filosofia del llenguatge aquest debat també resulta rellevant. Hem vist, per exemple, que la teoria designativa de Schlick i l'isomorfisme tenen moltes influencies de Wittgenstein, el qual és decisiu en tot el panorama analític del segle xx. A més, arran del problema plantejat per Gottlob Frege entorn dels conceptes de sentit i de referència (Frege, 1892), la distinció kantiana entre judicis analítics i sintètics constitueix un nou casus belli que no solament implica Carnap, Husserl, Schlick i Wittgenstein (cf. Piana, 1971), sinó que també interessa a Willard van Orman Quine (cf., per exemple, Quine, 1951). Tampoc s'ha d'oblidar un altre aspecte típic d'aquest context teòric: el relativisme ontològic proposat pel propi Quine (cf. Quine, 1969). Com sabem, aquesta teoria suggereix la necessitat filosòfica d'abandonar tota referència o correspondència objectual, $i$ evidentment apropa la investigació lingüística i analítica al concepte de funció de Cassirer. Independentment de les diferències que els separen (cf. Massimi, 2009; Richardson, 2015), és evident que quan ésser no té cap més significat que el valor d'una variable vinculada (Quine, 1948), no solament hem perdut una realitat en si i hem obtingut ontologies diferents que varien segons teories i llenguatges diversos sense perdre necessàriament la idea de veritat (cf. Valore, 2012), sinó que s'ha reivindicat també la necessitat d'abandonar «l'esperança de presentar exhaustivament el conjunt de la natura mitjançant un sol sistema de símbols» (Cassirer, 1937: 265)12.

4. En quart lloc i per acabar, aquesta anàlisi és d'una importància capital també perquè permet reflexionar entorn del llegat de Kant des de la perspectiva molt específica de la filosofia de la física. Si el punt de vista neokantià és correcte (o almenys acceptable), aleshores l'exemple de les cireres mostra que qualsevol objecte de la realitat (no importa si ens és donat o no) no es converteix en cap signe per nosaltres fins que no li és atribuït un sentit. Aquesta observació porta a una conclusió fonamental: la filosofia crítica és una teoria del significat en tant que la seva tasca consisteix a fonamentar la manera com té sentit parlar d'un objecte en general ${ }^{13}$. Aquest és efectivament el compromís de l'apriorisme kantià un cop ha estat dinamitzat i desvinculat de les limitacions històriques i culturals imposades per Kant. De fet, si per a priori entenem únicament «els últims invariants

12. Hem vist que, des d'un cert punt de vista, la fonamentació filosòfica d'aquest plantejament es troba ja a la Crítica del judici (Kant, 1968c). Tot i això, cal evidenciar també que l'«empirisme sense dogmes», de Quine, no és compatible in toto amb la instància neokantiana: el relativisme ontològic potser n'és simplement el punt de contacte menys problemàtic.

13. Les paraules de Kant respecte a aquesta qüestió són molt clares: «el coneixement d'un objecte implica poder-ne demostrar la possibilitat» (Kant, 1968b: 17n (B XXVI)) (cf. també Cardani, 2016, 2017). 
lògics que, de forma general, es troben a la base de qualsevol determinació de les lleis de la natura», aleshores "un coneixement no es diu a priori com si es trobés en un cert sentit abans de l'experiència, sinó en tant que és contingut com a premissa necessària en qualsevol judici que concerneix uns fets» (Cassirer, 1910: 356).

Això significa, per tant, que el rude dualisme que molts crítics van atribuir a Kant, i que consisteix en l'assumpció de coses fora de nosaltres i independents de l'activitat de l'enteniment, es deu a un error fonamental: l'error de no reconèixer que el veritable problema, per a Kant, és la determinació, en els termes més generals, del significat de la realitat i de l'ésser, però no la mera reconstrucció mecànica del coneixement (cf., per exemple, Cardani, 2016; Cardani i Tamborini, 2017).

En conseqüència, aquest debat ensenya que els esforços d'actualitzar Kant portats a terme pels seus seguidors (com precisament ho és Cassirer), però també per alguns dels seus detractors (com ara, per exemple, Johann F. Herbart (cf. Herbart, 1828)), resulten fonamentals per conservar la instància crítica sense perdre's en la contingència (i els errors puntuals) de la lletra. Així doncs, si volguéssim reemplaçar la terminologia kantiana amb la més dinàmica del neokantisme de Cassirer, notaríem un acord substancial en la solució dels problemes de fons.

De fet, a Substanzbegriff und Funktionsbegriff(Cassirer, 1910), la doctrina kantiana de l'esquematisme i la controvertida deducció transcendental són reemplaçades per la teoria del concepte de funció, que és capaç de recosir la ruptura amb l'evolució científica i a l'hora de mantenir competitiu el criticisme sense alterar el seu missatge més significatiu.

Quan Cassirer afirma que qualsevol judici a posteriori implica sempre i en tot cas un element a priori (cf. Cassirer, 1910), vol efectivament indicar que qualsevol judici cognoscitiu que es refereixi a un objecte ha de poder conferir significat al seu referent. La constitució del significat mitjançant la introducció d'allò que ens és donat en el sistema relacional de la pluralitat matemàtica és possible justament gràcies a principis lògics superiors assumits com a condicions de possibilitat de tota l'experiència.

És cert: ens separen més de 70 anys de la mort de Cassirer i més de 200 de la mort de Kant, i avui, evidentment, podem analitzar aquests problemes amb ulls decididament més objectius. Té raó Friedman: Einstein va provocar un debat increïble dins del món filosòfic, i la teoria de la relativitat no pot ser incorporada a la filosofia transcendental tan facilment com va suggerir Cassirer (cf. Cassirer, 1910, 1921, 2010) ${ }^{14}$. Tot i això, arran dels problemes proposats en aquest article, encara sembla correcte afirmar que:

14. Cassirer no sols creu que la teoria de la relativitat és compatible amb la doctrina de Kant, sinó que, si concebem les intuïcions kantianes d'espai i temps com a formes de la intuïció objectives però no absolutes, «la doctrina kantiana de l'espai i del temps resulta brillantment confirmada per la teoria de la relativitat» (Cassirer, 2010: 113) (cf. també Coffa 1991). 
Lúnica manera d'avançar consisteix a relativitzar l'apriorisme kantià a una teoria científica donada en un context històric particular i, consegüentment, a historicitzar la noció mateixa de filosofia transcendental. (Friedman, 2010: 186)

Aquest camí consisteix a descobrir aquells elements formals que resten constants en tots el canvis dels elements particulars continguts en els materials de l'experiència, amb la finalitat de donar sentit a la pregunta entorn de la realitat, i a configurar el sistema original de Kant arran dels progressos de la filosofia científica postkantiana i de les ciències mateixes. Amb una renovació de la teoria crítica de l'experiència portada a terme d'aquesta manera, la filosofia pot tornar a dialogar amb la ciència i amb les diverses formes culturals en l'àmbit dels seus principis, $\mathrm{i}$ «el concepte complet de pensament restableix l'harmonia amb l'ésser» (Cassirer, 1910: 432).

\section{Referències bibliogràfiques}

Beneke, Friedrich E. (1832). Kant und die philosophische Aufgabeunserer Zeit: Eine Jubeldenkschrift auf die Kritik der reinen Vernunft. Berlín: Mittler.

Bergmann, Peter G. (1970). "Ernst Mach and Contemporary Physics». A: Cohen, Robert S. i Seeger, Raymond J. Ernst Mach: Physicist and Philosopher. Dordrecht: Reidel, 69-78.

Bogen, James (2009). "'Saving the phenomena" and saving the phenomena». Synthese, 182, 149-163. <https://doi.org/10.1007/s11229-009-9619-4>

Bogen, James i Woodward, James (1988). "Saving the Phenomena». The Philosophical Review, 97, 303-352. <https://doi.org/10.2307/2185445>

CARDANI, Michele (2016). «Vuelta a la realidad: Nuevo realismo contra Kant». A: Navarro Cordón, Juan M.; Orden Jiménez, Rafael V. i Rovira, Virgilio. Nuevas perspectivas sobre la filosofía de Kant. Madrid: Escolar y Mayo, 57-66.

- (2017). Forma y contenido: Una interpretación del idealismo británico. Barcelona: Universitat de Barcelona. Tesi doctoral. Recuperat de $<\mathrm{http}: / / \mathrm{hdl}$. handle.net/2445/112766>.

Cardani, Michele i Tamborini, Marco (2016). «Data-Phenomena: Quid Juris?». Zeitschrift für philosophische Forschung, 70, 527-549. <https://doi.org/10.3196/004433016820168266>

- (2017). «Italian New Realism and Transcendental Philosophy: A Critical Account». Philosophy Today, 61, 539-554.

$<$ https://doi.org/10.5840/philtoday2017919170>

Carnap, Rudolf (1995). The Unity of Science. Bristol: Thoemmes.

CASSIRER, Ernst (1910). Substanzbegriff und Funktionsbegriff: Untersuchungen über die Grundfragen der Erkenntniskritik. Berlín: Bruno Cassirer.

- (1921). Zur Einsteinschen Relativitätstheorie: Erkenntnistheoretische Betrachtungen. Berlín: Bruno Cassirer. 
- (1937). Determinismus und Indeterminismus in der Modernen Physik: Historische und Systematische Studien zum Kausalproblem. Göteborg: Elanders Boktryckeri Aktiebolag.

- (2000). «Von Hegels Tod bis zur Gegenwart (1832-1932)». A: Berben, Tobias i Vogel, Dagmar (eds.). Gesammelte Werke: Hamburger Ausgabe, Band 5. Das Erkenntnisproblem in der Philosophie und Wissenschaft der neueren Zeit. Vierter Band. Hamburg: Meiner.

- (2001). «Philosophie der symbolischen Formen. Erster Teil: Die Sprache». A: Rosenkranz, Claus (ed.). Gesammelte Werke: Hamburger Ausgabe, Band 11. Hamburg: Meiner.

- (2002). «Philosophie der symbolischen Formen. Dritter Teil: Phänomenologie der Erkenntnis». A: Clemens, Julia (ed.). Gesammelte Werke: Hamburger Ausgabe, Band 13. Hamburg: Meiner.

- (2004). «Erkenntnistheorie nebst den Grenzfragen der Logik und Denkpsychologie». A: Berben, Tobias (ed.). Gesammelte Werke: Hamburger Ausgabe, Band 17. Aufsätze und kleine Schriften (1927-1931). Hamburg: Meiner, 13-81.

- (2010). «Die philosophischen Probleme der Relativitätstheorie». A: FinGerhut, Jörg; Hartung, Gerald i Kramme, Rüdiger (eds.). Nachgelassene Manuskripte und Texte, Band 8: Vorlesungen und Vorträge zu philosophischen Problemen der Wissenschaften. Hamburg: Meiner, 29-116.

Coffa, J. Alberto (1991). The Semantic Tradition From Kant To Carnap: The Vienna Station. Wessels, Linda (ed.). Cambridge: Cambridge University Press.

Esposito, Maurizio (2016). Romantic Biology, 1890-1945. Londres: Routledge. FREGE, Gottlob (1892). «Über Sinn und Bedeutung». Zeitschrift für Philosophie und philosophische Kritik, 100, 25-50.

French, Steven i Ladyman, James (2003). «Remodelling Structural Realism: Quantum Physics and the Metaphysics of Structure». Synthese, 136, 31-56. $<$ https://doi.org/10.1023/A:1024156116636>

Friedman, Michael (1999). Reconsidering Logical Positivism. Cambridge: Cambridge University Press.

- (2000). A Parting of the Ways: Carnap, Cassirer, and Heidegger. Chicago: Open Court.

- (2010). «Ernst Cassirer and Thomas Kuhn: The Neo-Kantian Tradition in the History and Philosophy of Science». A: Makkreel, Rudolf A. i Luft, Sebastian. Neo-Kantianism in Contemporary Philosophy. Bloomington: Indiana University Press, 177-191.

GaliLeI, Galileo (1965). Il saggiatore. Milà: Feltrinelli.

Glymour, Bruce (2000). «Data and Phenomena: A Distinction Reconsidered». Erkenntnis, 52, 29-37.

$<$ https://doi.org/10.1023/A:1005499609332>

Goenner, Hubert (1970). «Mach's Principle and Einstein's Theory of Gravitation». A: Cohen, Robert S. i Seeger, Raymond J. Ernst Mach: Physicist and Philosopher. Dordrecht: Reidel, 200-215. 
Gower, Barry (2010). «Cassirer, Schlick and "Structural Realism”: The Philosophy of the Exact Sciences in the Background to Early Logical Empiricism». British Journal for the History of Philosophy, 8, 71-106. <https://doi.org/10.1080/096087800360238>

Hahn, Hans; Neurath, Otto i Carnap, Rudolf (2002). Wissenschaftliche Weltauffassung: Der Wiener Kreis. Viena: Artur Wolf Verlag. Traduït al castellà per P. Lorenzano. «La concepción científica del mundo: El Círculo de Viena». Redes, 9, 103-149.

Haller, Rudolf (1991). «The First Vienna Circle». A: Uebel, Thomas E. Rediscovering the Forgotten Vienna Circle. Dordrecht: Kluwer, 95-108.

Herbart, Johan F. (1828). Allgemeine Metaphysik, nebst den Anfängen der philosophischen Naturlehre. Königsberg: Unzer.

KaNT, Immanuel (1968a). Metaphysische Anfangsgründe der Naturwissenschaft. Akademie Textausgabe, Bd. IV. Berlín: De Gruyter, 465-565.

- (1968b). Kritik der reinen Vernunft. 2: Auflage 1787. Akademie Textausgabe, Bd. III. Berlín: De Gruyter.

- (1968c). Kritik der Urtheilskraft. Akademie Textausgabe, Bd. V. Berlín: De Gruyter, 165-485.

Liano, Luigi (2016). «Ernst Cassirer e la biologia: Dall'evoluzionismo alla paleoantropologia come scienza trascendentale dell'uomo». Scienza e Filosofia, 16, 116-130.

Livingston, Paul (2002). «Husserl and Schlick on the Logical Form of Experience». Synthese, 132, 239-272. <https://doi.org/10.1023/A:1020378731241>

MACH, Ernst (1889). Die Mechanik in ihrer Entwicklung: Historisch-kritisch dargestellt. Leipzig: Brockhaus.

- (1906). Erkenntnis und Irrtum: Skizzen zur Psychologie der Foerschung. Leipzig: Barth.

Mascheroni, Lorenzo (1863). Poesie. Florència: Le Monnier.

Massimi, Michela (2009). «Philosophy and the Sciences After Kant». Royal Institute of Philosophy Supplement, 65, 275-311. <https://doi.org/10.1017/S1358246109990142>

- (2011). «From data to Phenomena: A Kantian Stance». Synthese, 182, 101116. <https://doi.org/10.1007/s11229-009-9611-z>

Midgley, Mary (2018). What is Philosophy for? Londres: Bloomsbory.

PARrini, Paolo (2002). L'empirismo logico: Aspetti storici e prospettive teoriche. Roma: Carocci.

Piana, Giovanni (1971). «Husserl, Schlick e Wittgenstein sulle cosiddette "proposizioni sintetiche a priori"”. AutAut, 122, 19-41.

PoinCARÉ, Henry (1917). La Science et l'Hypothèse. París: Flammarion.

Quine, Willard van Orman (1948). "On What There Is». Review of Metaphysics, 2, 21-38.

- (1951). «Main Trends in Recent Philosophy: Two Dogmas of Empiricism». The Philosophical Review, 60, 20-43. 
- (1969). Ontological Relativity and Other Essays. Nova York: Columbia University Press.

Richardson, Alan W. (2015). "Holism and the Constitution of "Experience in its Entirety": Cassirer contra Quine on the Lessons of Duhem». A: Friedman, J. Tyler i Luft, Sebastian. The Philosophy of Ernst Cassirer: A Novel Assessment. Berlín: De Gruyter, 103-122.

Rodríguez Consuegra, Francisco (1993). «L'origen de la construcció lògica fenomenalista: Mach, Moore y Whitehead». Enrahonar, 20, 31-55. <https://doi.org/10.5565/rev/enrahonar.546>

Schlagel, Richard H. (1992). "Resolving the Realist-Antirealist Dilemma». A: Cohen, Robert S.; Hilpinen, Risto i Renzong, Qiu. Realism and Anti-Realism in the Philosophy of Science. Dordrecht: Kluwer, 405-417.

ScHuIcK, Moritz (1920). Raumund Zeit in der gegenwärtigen Physik Zur Einführung in das Verständnis der Relativitäts-und Gravitationstheorie. Berlín: Springer.

- (1921) «Kritizistische oder empiristische Deutung der neuen Physik?: Beemerkungen zu Ernst Cassirers Buch "Zur Einsteinschen Relativitätstheorie"». Kant Studien, 26, 96-111.

- (1925). Allgemeine Erkenntnislehre. Berlín: Springer.

- (1938). Form and Content: An Introduction to Philosophical Thinking. A: Gesammelte Aufsatze, 1926-1936. Viena: Gerold, 151-249.

- (2009). «Moritz Schlick an Ernst Cassirer, 30 März 1927». A: Cassirer, Ernst. Nachgelassene Manuskripte und Texte, Band 18: Ausgewählter wissenschaftlicher Briefwechsel. KroIs, John Michael (ed.). Hamburg: Meiner, 94-98.

TAMborini, Marco (2018). «Dati, epistemologia storica e spazi di conoscenza paleontologica». Iride, 31, 49-65. <https://doi.org/10.1414/90187>

- (en curs). "Series of Forms, Visual Techniques, and Quantitative Devices: Ordering the World Between the End of the 19th and Early 20th Centuries». History and Philosophy of the Life Sciences.

Tinland, Olivier (2017). «Hegel critique de Kant: Éléments pour la généalogie d'un empirisme de la raison». A: Grandjean, Antoine (ed.). Kant et les empirismes. París: Garnier, 155-172.

Valore, Paolo (2012). La sentenza di Isacco: Come dire la verità senza essere realisti. Milà-Udine: Mimesis.

Von Mises, Richard (1970). "Mach and the Empiricist Conception of Science». A: Cohen, Robert S. i Seeger, Raymond J. Ernst Mach: Physicist and Philosopher. Dordrecht: Reidel, 245-270.

Zammitto, John H. (2018). The Gestation of German Biology: Philosophy and Physiology from Stahl to Schelling. Chicago: The University of Chicago Press. 
Michele Cardani (Itàlia, 1987) és doctor en Filosofia Contemporània i Estudis Clàssics per la Universitat de Barcelona i la Universitat de Milà. La seva tesi sobre l'idealisme britànic va ser codirigida pels professors Salvi Turró i Renato Pettoello. És membre del Grup d'Estudis de Filosofia Clàssica Alemanya (GEFCA) de la Societat Catalana de Filosofia i s'interessa per la història de l'idealisme, la filosofia postkantiana i la renovació del transcendental. Les seves publicacions més destacades són: «Die Frage nach dem wirklichen Julius Cäsar - und warum sie immer noch aktuell», Deutsche Zeitschrift für Philosophie, 67, 2019, 392-413 (amb Marco Tamborini); «Vuelta a la realidad: Nuevo realismo contra Kant», a: R. V. Orden Jiménez et al. (eds.), Nuevas perspectivas sobre la filosofía de Kant, Madrid, Escolar y Mayo, 2016, 57-66; «La copia in gesso di un uomo vivente: Perché, di nuovo, Kant?», Humanitas, 71, 2016, 438-451, i «"Por un puñado de... táleros": Existencia y contenido empírico en F. H. Bradley», Comprendre: Revista Catalana de Filosofia, 16, 2014, 51-70.

Michele Cardani (Italy, 1987) holds a PhD in Contemporary Philosophy and Classical Studies from the University of Barcelona and the University of Milan. His thesis on British idealism was co-directed by Professors Salvi Turró and Renato Pettoello. He is a member of the Classical German Philosophy Study Group (GEFCA) of the Catalan Society of Philosophy and is interested in the history of idealism, post-Kantian philosophy and the renewal of the transcendental. His most relevant publications include "Die Frage nach dem wirklichen Julius Cäsar - und warum sie immer noch aktuell ist», Deutsche Zeitschrift für Philosophie, 67, 2019, 392-413 (with Marco Tamborini); "Vuelta a la realidad: Nuevo realismo contra Kant" in R.V. Orden Jiménez et al. (eds.), Nuevas perspectivas sobre la filosofia de Kant, Madrid: Escolar y Mayo, 2016, 57-66; "La copia in gesso di un uomo vivente. Perché, di nuovo, Kant?", Humanitas (2016), 71, 438451; “'Por un puñado de... táleros'. Existencia y contenido empírico en F. H. Bradley”, Comprendre: Revista catalana de filosofía (2014), 16, 51-70. 